\title{
Psychological distress among university students
}

We write in response to the paper titled "Psychological distress among students from five universities" (1). It has weaknesses in its design, statistics, analysis and interpretation.

Design

The study population of 350 comes from 5 universities, but the selection of the sample is not adequately described. Were the random sample stratified according to the university or the year of entry, and did they calculate the desirable sample size?

Selection of the control sample is also unclear. Does the "respective communities" (mentioned only in the abstract) mean that each student was matched for the area they hail from? This is important as the authors use a variable rural, sub-urban and urban sample in their analysis and conclusions.

Analysis of General Health Questionnaire (GHQ) scores

Analysis of GHQ scores only by dichotomising them to psychologically distressed and non-distressed by a cutoff score is misleading, because the GHQ is a screening questionnaire, higher the GHQ scores, higher the probability of underlying distress or common mental disorder. Therefore, mean scores and difference between the means with their

essed in both samples). It is wrong to pool psychologically distressed in two groups that are being compared. The correct comparison of distressed males would have been $69.2 \%$ (71/ 104) vs $64.1 \%$ (43/67) [distressed males/total distressed in the university sample vs distressed males/total distressed in the community sample) and the difference, $5.1 \%$ is not significant. SE of the difference is 7.07 and therefore $95 \%$ CI would be 8.65 to 18.95 . As CI includes 0 the difference is 
not significant. One reason for this wide confidence intervals and non-significance (type II error) may be due to low power resulting from inadequate sample size because it had not been calculated in advance (4).

Had they used the same principle for calculating females' percentages, the figures given in the paper are completely wrong (32/171 shold be $18.7 \%$ and $24 / 171$ is $14 \%)$. Correct comparison should be $30.8 \%$ (32/104) vs $35.8 \%$ (24/76). Had they correctly applied Chi-square to the Table 1 , the value would be 0.47 , which is not significant.

The word limitation for correspondence prevents us from critically evaluating this paper any further.

\section{References}

1. Kuruppuarachchi KALA, Kuruppuarachchi KAJM, Wijeratne S, Williams SS. Psychological distress among students from five universities in Sri Lanka. Ceylon Medical Journal 2002; 47: 13-5.

2. Gardner MJ, Altman DG. Confidence intervals rather than $P$ values: estimation rather than hypothesis testing. British Medical Journal 1986; 292: 746-50.

3. Odell SM, Surtees PG, Wainwright NWJ, Commander MJ, Sashidharan SP. Determinants of general practitioner recognition of psychological problems in a multi-ethmic inner-city health district. British Journal of Psychiatry 1997; 171: 537-41.

4. Altman DG. Practical statistics for medical research. London: Chapman and Hall, 1997: 169.

A Sumathipala, Research Psychiatrist, Institute of Psychiatry, Kings College, University of London, London, UK and S Siribaddana, Staff Specialist in Medicine, Sri Jayewardenepura Postgraduate Teaching Hospital, Nugegoda. (Correspondence to AS telephone 01 578336, e-mail: spjuats@iop.kcl.ac.uk). 